\title{
Genetics and morphology of the genus Tritetrabdella (Hirudinea, Haemadipsidae) from the mountainous rain forests of Sabah, Borneo, reveal a new species with two new subspecies
}

\author{
Heike Kappes ${ }^{1,2,3}$ \\ ${ }^{1}$ Naturalis Biodiversity Center, Postbus 9517, 2300 RA Leiden, The Netherlands \\ ${ }^{2}$ Department of Ecology, Cologne Biocenter, University of Cologne, Zülpicher Str. 47b, 50674 Köln, Germany \\ ${ }^{3}$ Email: heike.kappes@uni-koeln.de
}

Key words: Annelida, Clitellata, ecological specialization, genetic distance, parasite, phylogeny, speciation, tropical mountains

\begin{abstract}
Blood-feeding terrestrial leeches of the family Haemadipsidae are a notorious part of the invertebrate diversity in Asian and Australian rain forests. All hitherto published records of terrestrial leeches of Borneo belong to the genus Haemadipsa. Here, a second, poorly known haemadipsid genus is reported from Mount Kinabalu and Crocker Range National Park. The individuals were barcoded and compared to sequences available in GenBank. The results show that the genus Tritetrabdella has representatives in the Indochinese and the Sundaic bioregions. All six specimens from Borneo are from a single new Tritetrabdella lineage, $T$. kinabaluensis spec. nov. Within the Bornean lineage, two groups differing $4-5 \%$ in the COI barcoding sequence were identified. Because 1) it is probable that haemadipsid COI is subjected to base pair substitution rates of $2.5 \%$ per $\mathrm{Ma}, 2$ ) COI protein sequences were the same within the Bornean material, 3) color can change as a response to the environment, 4) the lineages inhabit different altitudes in separate areas and 5) only six individuals were found, a conservative approach was taken and the groups were tentatively given subspecies status: T. k. kinabaluensis ssp. nov. and $T$. $k$. inobongensis ssp. nov. The ecology and the conservation status of the Bornean Tritetrabdella warrant urgent assessment because the genus Tritetrabdella is considered as mainly feeding on amphibians and probably small mammals, and thus can be predicted to be sensitive to climatic fluctuations, forest disturbances and fragmentation, and amphibian decline.
\end{abstract}

\section{Contents}

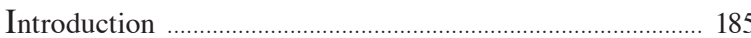

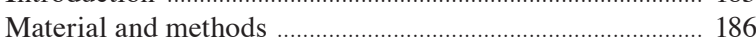

Specimens ............................................................................. 186

DNA extracting and sequencing ...................................... 186

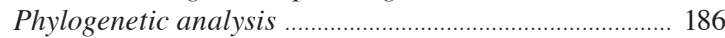

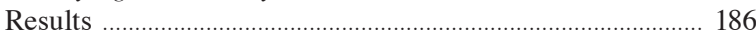

Phylogenetic position of the Bornean specimens ........... 186

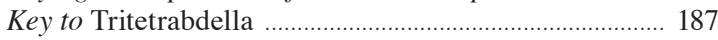

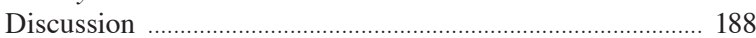

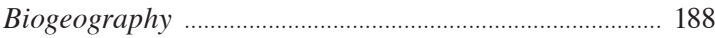

Rough timing with geological events ................................ 188

Intraspecific and interspecific divergence ...................... 190

Knowledge gaps: ecology and conservation status ....... 190
Acknowledgements ………………………………….............. 191

References .............................................................................. 191

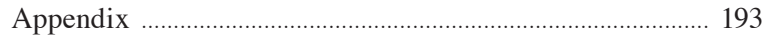

\section{Introduction}

Almost every traveler sooner or later encounters the terrestrial, blood-sucking haemadipsid leeches while exploring the Bornean rainforests, but not much has been published on the leech fauna of Borneo after the two initial papers of Moore $(1929,1935)$ and the review of Smythies (1960). According to Smythies (1960), Borneo harbors three Haemadipsid species, namely Haemadipsa picta (Moore, 1929), H. sylvestris Blanchard, 1894, and H. zeylanica (Moquin-Tandon, 1826) with three to four subspecies. The occurrence of $H$. sylvestris, however, is based on speculations (Smythies, 1960: 286). Govedich et al. (2004) mention only $H$. picta and two subspecies of H. zeylanica for Borneo.

During the Mount Kinabalu and Crocker Range Expedition in September 2012, leeches were collected near several substations of Sabah Parks on Mount Kinabalu and the Crocker Range. Five individuals from the Crocker Range, and one from Mount Kinabalu Headquarters were identified to belong to the poorly studied genus Tritetrabdella Moore, 1938. Tritetrabdella leeches seem to be specialized in amphibians and small mammals (Lai et al., 2011). Members of this genus are smaller than those of Haemadipsa, have four annuli per mid-body somite, the gonopores separated by only 3-3.5 annuli, and a posterior sucker with less than 60 rays (Moore, 1938).

So far, two Tritetrabdella species have been described. Tritetrabdella scandens Moore, 1938 occurs on the Malaysian Peninsula (Moore, 1938) and Taiwan (Borda and Siddall, 2011). Tritetrabdella taiwana (Oka, 1910) is distributed across Taiwan, the Indo-Chinese Peninsula, and the Ryuku Island of Japan (Lai et al., 
2011). This study thus provides the first record of the genus Tritetrabdella on Borneo. Based on the barcoding sequence of the cytochrome c oxidase subunit I gene and morphological data, a new species with two subspecies will be described.

\section{Material and methods}

\section{Specimens}

Four of the Crocker Range individuals originate from the forests at Inobong substation, downstream of the Sungai Kibambangan waterfall, and one individual climbed one of the expedition participants of the expedition at the Gunung Alab substation. An additional individual was found climbing on an expedition participant at Kinabalu Park Headquarters. The material is designated to be (re-)located to the Sabah Parks zoological collection in 2014.

\section{DNA extraction and sequencing}

The material was barcoded using the cytochrome $\mathrm{c}$ oxidase subunit I gene (COI). To this end, a piece of the epithelium of the lower belly above the caudal sucker was cut and placed in 98\% ethanol. DNA extraction was performed on this subsample using the NucleoMag 96 Tissue kit by Macherey-Nagel on a Thermo Scientific KingFisher Flex magnetic bead extraction robot in a final elution volume of $150 \mu 1$. The COI barcoding fragment (658 bp) was amplified using a cocktail of the primers LCO1490 and HCO2198 (Folmer et al., 1994), and LepF1 and LepR1 (Hebert et al., 2004a). Primers were tailed using M13F and M13R (Messing, 1983) for sequencing. PCR reactions contained $18.75 \mu \mathrm{lmQ}, 2.5 \mu \mathrm{l} 10 \mathrm{x}$ CoralLoad PCR buffer CL, $1.0 \mu \mathrm{l} 10 \mathrm{mM}$ of each primer, 0.5 $\mu 12.5 \mathrm{mM}$ dNTPs and $0.25 \mu 1$ 5U Qiagen Taq and $1.0 \mu 1$ template DNA. The thermal cycle program consisted of an initial denaturation step of $3 \mathrm{~min}$ at $94^{\circ} \mathrm{C}$, followed by 40 cycles of $15 \mathrm{~s}$ denaturation at $94^{\circ} \mathrm{C}, 30 \mathrm{~s}$ annealing at $50^{\circ} \mathrm{C}$ and 40 s elongation at $72^{\circ} \mathrm{C}$, with a final elongation of $5 \mathrm{~min}$ at $72^{\circ} \mathrm{C}$. Bidirectional sequencing was done by BaseClear. The resulting sequences were deposited in GenBank (accession numbers KF839944-KF839949).

\section{Phylogenetic analysis}

The main scope was to assess if the Bornean material falls within one of the two hitherto described species. The COI sequences were compared to those from other
Haemadipsidae from GenBank. Genetic distances between the barcoding sequences of the taxa were calculated as the number of base substitutions per site using DNADIST (vers. 3.5c).

DNA and protein sequences were used to visualize potential phylogenetic relationships. The DNA sequences were translated into a protein sequences using the general invertebrate code in MEGA 4.0 (Tamura et al., 2007). Distances were calculated as the number of base pair or amino acid substitutions per site. After complete deletion of missing data, there were a total of $612 \mathrm{bp}$ and 204 amino acid positions in the dataset of the barcoding sequence and protein sequence, respectively.

Because the main scope is taxonomic and the available sequences reflect only a fraction of the evolutionary history, and of the mitochondrion alone, a conservative approach was taken both in terms of phylogenetic analysis and in terms of interpretation (e.g. Britton et al., 2007; Wägele et al., 2009). For each data set, the DNA sequences and the corresponding protein sequences, a consensus tree was constructed from 500 bootstrap runs using the Neighbor-Joining method. Poisson correction was applied in the case of the protein sequences. In the graph, the percentage of replicate trees in which the taxa clustered together as a group in the bootstrap test (500 replicates) were displayed next to the branches. Both trees were drawn to scale, with branch lengths in the same units as those of the evolutionary distances used to infer the phylogenetic tree. Phylogenetic analyses were conducted in MEGA 4.0 (Tamura et al., 2007).

\section{Results}

Phylogenetic position of the Bornean specimens

The Bornean individuals (GenBank accession numbers KF839944-KF839949) have more than 15\% distance in the partial COI barcoding sequence when, for example, compared to Tritetrabdella scandens (GenBank accession number HQ203194) and T. taiwana (GenBank accession number HQ322464) from the mainland (Table 1). Tritetrabdella taiwana displays divergences similar to between-species distances in other Haemadipsidae (>12\%, Fig. 1). The sequences from $T$. taiwana thus likely originate from a species complex. However, the COI sequence data of T. taiwana also suggests that rapid evolution can take place, and that differences of $4-5 \%$ in the COI barcoding sequence may still be accounted to intraspecific variability. Indeed, the corresponding protein sequences are highly similar within the 
Table 1. Uncorrected pairwise distances in the COI barcoding region of Tritetrabdella. COI-clone i1 was found in three individuals (collection numbers SP13381, 13382, 13383) COI-clones i2, k1 and k2 were each extracted from a single individual (SP13380, SP13398 and SP13306, respectively). i: subspecies inobongensis, k: subspecies kinabaluensis.

\begin{tabular}{|c|c|c|c|c|c|}
\hline & T. taiwana & T. spec. nov. (i1) & T. spec. nov. (i2) & T. spec. nov. $(k 1)$ & $T$. spec.nov. $(k 2)$ \\
\hline T. scandens [GenBank, HQ203194] & 0.1582 & 0.1739 & 0.1737 & 0.1688 & 0.1587 \\
\hline T. taiwana [GenBank, HQ322464] & 0.0000 & 0.1695 & 0.1655 & 0.1717 & 0.1665 \\
\hline T. $k$. spec. nov. COI-clone i1 & - & 0.0000 & 0.0046 & 0.0475 & 0.0443 \\
\hline T. k. spec. nov. COI-clone i2 & - & - & 0.0000 & 0.0508 & 0.0476 \\
\hline T. k. spec. nov. COI-clone k1 & - & - & - & 0.0000 & 0.0092 \\
\hline T. k. spec. nov. COI-clone $\mathrm{k} 2$ & - & - & - & - & 0.0000 \\
\hline
\end{tabular}

\begin{tabular}{|c|c|c|c|c|c|c|}
\hline & A & $\mathrm{C}$ & G & $\mathrm{T}$ & $\mathrm{G}+\mathrm{C}$ & $\mathrm{A}+\mathrm{T}$ \\
\hline \multicolumn{7}{|c|}{ T. k. kinabaluensis ssp. nov. } \\
\hline COI-clone k1 & 29.64 & 14.74 & 14.74 & 40.88 & 29.48 & 70.52 \\
\hline COI-clone k2 & 29.94 & 14.44 & 14.29 & 41.34 & 28.72 & 71.28 \\
\hline \multicolumn{7}{|c|}{ T. k. inobongensis ssp. nov. } \\
\hline COI-clone i1 & 30.24 & 15.20 & 14.29 & 40.27 & 29.48 & 70.52 \\
\hline COI-clone i2 & 29.94 & 15.20 & 14.44 & 40.43 & 29.64 & 70.36 \\
\hline
\end{tabular}

Table 2. Base composition characteristics in the 658 bp barcoding region of COI (in percentage) in the new species. assumed species complex, and strictly conserved within the Bornean Tritetrabdella (sub-)species (Fig. 2).

The Bornean Tritetrabdella form a distinct, monophyletic Tritetrabdella lineage (Figs 1,2). The consensus trees suggest that the genus Tritetrabdella evolved in Borneo or the Malaysian Peninsula, or in between. However, the exact geographic origin of Tritetrabdella cannot be assessed from the recent data set, since there is only one sequence available for T. scandens and the splitting points of the species lineages are not well supported by bootstrap values (Fig. 1).

The new Bornean species will hereafter be referred to as T. kinabaluensis spec. nov. This lineage is split in two groups, differing 4-5\% in the COI barcoding sequence. These two groups will tentatively be given subspecies status: T. k. kinabaluensis ssp. nov. and T. $k$. inobongensis ssp. nov. This conservative approach was taken because (1) the data from T. taiwana suggests that mutations in COI can accumulate rapidly in this group, (2) COI protein sequences were the same within the Bornean material, (3) coloration of animals may be variable, and (4) only few data from the new species is available. The partial COI sequence from the Bornean Tritetrabdella shows a compositional bias of about 70$71 \%$ A+T content (Table 2), which is similar to that in the T.taiwana complex (68-71\%) and T. scandens (69\%). Based on the few data available, the two subspecies amongst others seem to differ in the C-content, which is $<15 \%$ in T. k. kinabaluensis ssp. nov. and $>15 \%$ in $T . k$. inobongensis ssp. nov. (Table 2).

Key to Tritetrabdella

1a. Gonopores separated by 4.5-5 annuli, five annuli per mid-body segment, caudal sucker with $>65$ rays Haemadipsinae, genus Haemadipsa

1b. Gonopores separated by 3-3.5 annuli, four annuli per mid-body segment, caudal sucker with $<60$ rays Tritetrabdellinae, genus Tritetrabdella $\Rightarrow 2$

2a. yellowish back, stripe pattern outline blackish, stripes of same yellowish color as back (according to photograph in Borda and Sidall 2010); Peninsula Malaysia and Taiwan ..... Tritetrabdella scandens Moore, 1937

2b. yellowish back, stripe pattern outline dark or blackish, stripes brownish; Taiwan, Indo-Chinese Peninsula, Ryukyu Islands (Japan) Tritetrabdella taiwana (Oka, 1910) - species complex

2c. creamy-whitish to creamy-brownish back, stripe pattern outline brownish or blackish, stripes medium to dark brown; Borneo (Sabah - Mt. Kinabalu and Crocker Range) Tritetrabdella kinabaluensis spec. nov. with two subspecies $=>3$ 
3a. Dorsal stripe brownish with thick blackish outlines forming an adjacent row of longitudinal loops and a second row with occasional bubbles on a creamy-whitish-brown background, single bubbles reach the lateral stripe, despite of light areas overall appearance blackish-brown in the field, distal sucker pointed towards the front, mountain forests (1500-1900 m.a.s.1.), C-content of COI barcoding region $<15 \%$

Tritetrabdella kinabaluensis kinabaluensis ssp. nov.

3b. Dorsal stripe median brownish with darker brownish outlines, forming an adjacent row of longitudinal loops (and sometimes bubbles) on a yellowish-brown background, loops do not reach the lateral stripe, overall appearance yellowish-brownish in the field, distal sucker clearly pointed towards the front, lower altitude dipterocarp forests (400-500 m.a.s.1.), C-content of COI barcoding region $>15 \%$......

Tritetrabdella kinabaluensis inobongensis ssp. nov.

\section{Discussion}

\section{Biogeography}

The Mount Kinabalu and Crocker Range Expedition resulted in an unexpected finding of a new species from a leech genus that was until now not reported from Borneo, although the area has been visited by countless numbers of tourists and numerous researchers. Representatives of the genus Tritetrabdella probably were not recorded before because they usually occur in mountainous forests, mainly feed on amphibians and only occasionally on small mammals (Lai et al., 2011), and on superficial inspection resemble a juvenile of the genus Haemadipsa. The latter display a high variability in color pattern, and the occurrence of the genus Tritetrabdella was unexpected from available identification keys. The new records from Borneo are more than $1000 \mathrm{~km}$ from the mainland and thus substantially broaden our knowledge on the biogeographic distribution of the genus Tritetrabdella. The data on the genus Tritetrabdella so far is not sufficient to determine the geographic origin of the genus.

Although Borneo is a Southeast Asian island today, it was not always so in the past. The Southwestern parts of Borneo are a block that rifted from Australia during the Late Jurassic and in the Early Cretaceous joined the Mesozoic Sundaland Core (Hall, 2012, and references therein). Unfortunately, it is not clear if this and two other blocks that rifted along with it were continuously emerged microcontinents during their journey north.

Borneo then was connected by a land bridge to the Malaysian Peninsula. This connection lasted at least from the Paleogene (ca.60 Ma ago) to the Early Pliocene (5 Ma) (Lohman et al., 2011). Connections of Borneo to the mainland were possible in more recent times as well. Borneo is part of the shallow Sunda Shelf, and Pleistocene sea levels often were substantially below the present sea level (Hanebuth et al., 2000; Voris,
2000). At and below 75m, an extensive coastal plain connects the Sundaic biogeographic region to the Indochinese biogeographic region (Voris, 2000), which happened at almost regular intervals for more than ten times in the last 150,000 years (Woodruff, 2010). These sea level fluctuations have affected the distribution of many taxa in the region (e.g. Woodruff, 2010). Based on the geological history in the Sunda Shelf region, it seems worthwhile to look for the genus Tritetrabdella on Sumatra and Java as well.

\section{Rough timing with geological events}

Borda et al. (2008) suggest that the haemadipsid genus Haemadipsa started radiating eastward after the collision of the plate of India with mainland Asia. However, the regional tectonics are highly complex and there are different models for plate tectonics available. The eastern edge of the maximal theoretical extension of the Indian plate ('Greater India 2') might have been close to, but not joining, Burma about $50 \mathrm{Ma}$ ago, and only fusing its North with the Asian continent about $45 \mathrm{Ma}$ ago (Hall, 2012 and references therein). Marine sediments show that the ocean North of India did not close before 35 Ma ago (Aitchison et al., 2007). Yet, India might have collided with some intraoceanic island arc very close to Sumatra and Peninsula Malaysia about 55 Ma ago (Aitchison et al., 2007).

Considering Haemadipsa species from opposite ends of SE Asia, such as H. hainana from China [GenBank accession number HQ322473] and H. picta from Sarawak/Borneo [HQ203177], the genetic distance can be up to $20 \%$. Assuming that Haemadipsa indeed radiated about 50 Ma ago from India (Borda et al., 2008), this would translate into base pair substitution rates of approximately $2.5 \% \mathrm{Ma}^{-1}$. If India was the source of the Southeast Asian radiation and this source became connected only 40-35 Ma ago, base pair substitution rates would have to exceed $3 \% \mathrm{Ma}^{-1}$. 


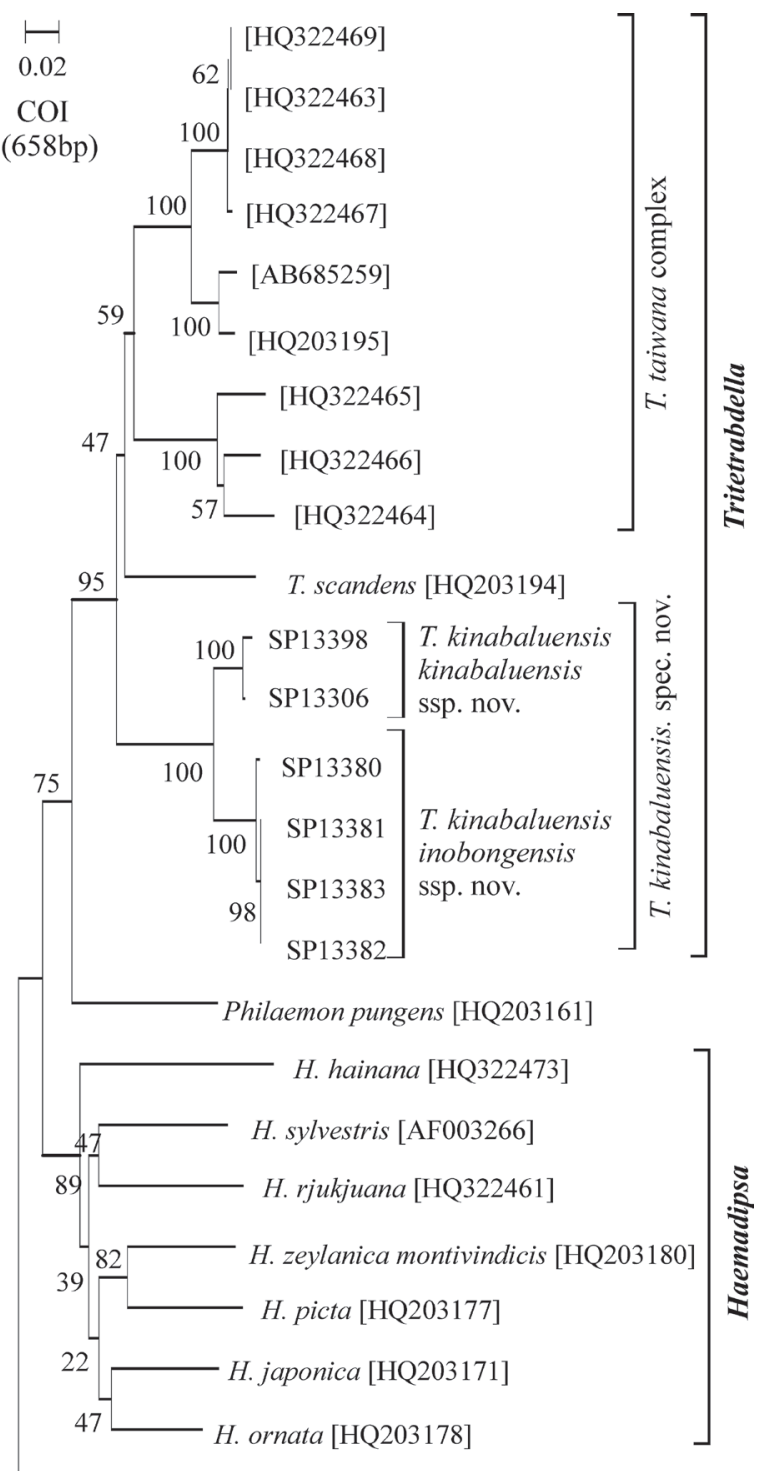

Hirudinaria manillensis [GQ368748]

Fig. 1. Hypothesis on the molecular phylogeny of the 658 bp barcoding sequence of the COI gene in Tritetrabdella, compared to other Haemadipsidae and the buffalo leech $H$. manillensis (Hirudinidae) as an outgroup (GenBank accession numbers in parentheses), showing monophyly of the Bornean Tritetrabdella (sub-)species, and a substantial intrataxon divergence in T. taiwana sequences that warrants future examination. The neighborjoining method and bootstrap values from 500 permutations were used for consensus tree construction in MEGA 4.0.

It has to be acknowledged that the timing of any other split is speculative, mainly based on the assumptions that (1) $2.5 \% \mathrm{Ma}^{-1}$ approximates the realized base pair substitution rate and (2) the genus Haemadipsa

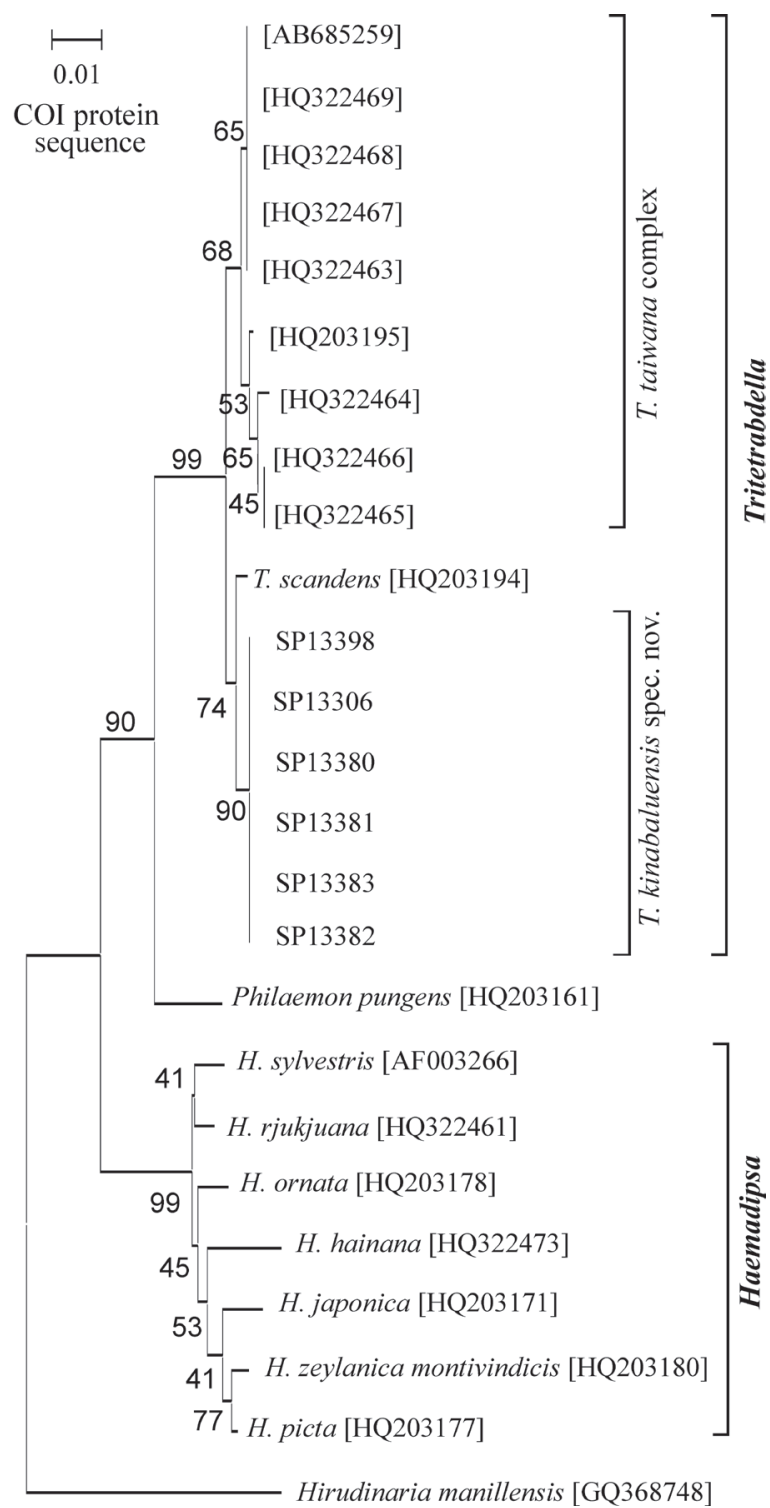

Fig. 2. Hypothesis on the phylogeny of Tritetrabdella based on the protein sequence from the barcoded partial COI gene, compared to other Haemadipsidae and the buffalo leech $H$. manillensis (Hirudinidae) as an outgroup (GenBank accession numbers in parentheses). Consensus tree construction was performed in MEGA 4.0 with the neighbor-joining method and bootstrap values from 500 permutations after translation using the invertebrate codon table.

displays the same mitochondrial base pair substitution rates as the genus Tritetrabdella. Tritetrabdella species that differ about $16-17 \%$ in COI sequence composition then could possibly have diversified about 40-42 Ma 
ago, that is, in the (late) Eocene. An alternative scenario would emerge if the rifting Australian blocks were not submerged and carried Gondwana species. The radiation of Tritetrabdella then might have taken place earlier, that is, when the rifting Australian blocks joined the Sunda area (90-115 Ma ago; Hall, 2012). In this case, base pair substitution rates within the genus Tritetrabdella would be in the range of, or even below, 1.6-1.7\% $\mathrm{Ma}^{-1}$. This would better fit in the molecular clock ranges suggested for invertebrates (Wilke et al., 2009).

Most of what today is Sabah was submerged from the Eocene to the late Miocene. This changed about 15-20 Ma ago when the Crocker Range mountain belt in Northern Borneo uplifted and folded, but this uplift soon ceased (Hall et al., 2008; Lohman et al., 2011). The mafic rocks that today are exposed on top of Mount Kinabalu seem to have formed $12 \mathrm{Ma}$ ago (Hall et al., 2008), crystallized only 7-8 Ma ago as a sheeted laccolith-like body (Cottam et al., 2010), and since then risen to an elevation up to $4 \mathrm{~km}$ above sea level (Hall et al., 2008).

The role of the uplift of Mount Kinabalu for the origin of the two subspecies remains to be scrutinized. Using the conventional substitution rates from Wilke et al. (2009), the split might well be $4 \mathrm{Ma}$ ago. Assuming substitution rates of $2.5 \% \mathrm{Ma}^{-1}$, however, the mitochondial lineages split only about 1.8-2 Ma ago (4.5-5\% sequence divergence).

About 1.8-2 Ma ago, continental glaciers developed that modified temperatures and rainfall patterns in Southeast Asia (Heaney, 1991). Mount Kinabalu was probably glaciated several times during the last $2 \mathrm{Ma}$ (Hall et al., 2008). Although climatic changes might have reinforced segregation and differentiation within T. kinabaluensis, it needs to be noted that the molecular clock of the subspecies living in cooler environments is expected to have slowed down with decreasing temperatures (Gillooly et al., 2005). The slightly shorter branch of T. k. kinabaluensis ssp. nov. in Fig. 1 thus might not be a sampling artifact, but an effect from cooler environments.

\section{Intraspecific and interspecific divergence}

The recent study, along with the sequence data from $T$. taiwana provided by Lai et al. (2011), suggests that the variability in the COI barcoding sequence within Tritetrabdella species exceeds the usual threshold of 3-4\% for separating species in several animal groups (e.g., Hebert et al., 2003), including the soil fauna (Rougerie et al., 2009). The threshold was proposed to be ten times the average intraspecific variation (Hebert et al., 2004b).

It might be derived from the genetic distances within the subspecies that the intraspecific threshold could be some $4-9 \%$. However, the intraspecific variation in the new species has not been sufficiently covered. Besides, some of the intraspecific divergences in $T$. taiwana might warrant taxonomic revisions.

Intraspecific divergences have been reported to reach between 4.9 and $7.4 \%$ in the spider Latrodectus hesperus (Barrett and Hebert, 2005), or 7.8\% in the earthworm species Eisenia fetida (Huang et al., 2007). This high intraspecific divergence indicates increased mutation rates, that is, rapid evolution, and/or cryptic speciation. The latter option might apply in both cases. The specimens assigned to Latrodectus hesperus were from two separated geographic regions with different climates (Barrett and Hebert, 2005). The genus Eisenia is rich in species in China, and the authors discuss the presence of a further, cryptic species (Huang et al., 2007). Similarly, the barcoding data suggests that the Indochinese biogeographic region may be richer in Tritetrabdella species than assumed, forming a T. taiwana species complex.

\section{Knowledge gaps: ecology and conservation status}

This study took a conservative approach and tentatively assigned subspecies status to the two Tritetrabdella lineages from Sabah. Ecological specialization such as on hosts or on climatic conditions may enhance mutation accumulation rates in Tritetrabdella, though the mutations were found to be ineffective because the corresponding protein sequence was conserved. Based on the few material that was available, it seems likely that the two Bornean subspecies are adapted to different habitats, namely low altitude dipterocarp forests and high mountain forests, in somewhat different parts of the Crocker Range. However, different climatic conditions could imply a different set of potential hosts. The role that the comparatively low ranges of passive dispersal on small vertebrate hosts plays in population divergence and metapopulation maintenance warrants further studies. Furthermore, yellowish or greyish body color may be a simple reaction to environmental conditions or food, as was shown for the slug Arion silvaticus (Jordaens et al., 2001). The exact taxonomic status of the Sabah material thus needs to be scrutinized from a higher number of individuals from more places, or by mating experiments. Future records from intermediate habitats will have to confirm or reject the 
hypothesis that the two subspecies are part of a cline.

Similarly, the ecology and the conservation status of the Tritetrabdella species urgently warrant assessment. Nevertheless, based on the little available information Tritetrabdella can be predicted to be sensitive to climatic fluctuations, habitat disturbances and forest fragmentation, as well as amphibian decline. The forest habitat protection provided within the boundaries of Sabah Parks and other nature conservation areas thus is crucial to conserve at least parts of the huge, hitherto still unexplored invertebrate diversity of Borneo.

\section{Acknowledgements}

Menno Schilthuizen (Naturalis, Leiden) and Maklarin Lakim (Sabah Parks, Kota Kinabalu) organized the Mount Kinabalu and Crocker Range Expedition. The board of trustees of Sabah Parks kindly permitted sampling and access. Herewith also a warm thanks to Rimi Repin (Sabah Parks) and the numerous helpful staff from Sabah Parks for the highly valued logistic support and overwhelming hospitality during the field stay. Nicolien Sol (Naturalis) found the Tritetrabdella specimen at Alab. Vincent S.F.T. Merckx (Naturalis) exported the samples for analysis at Naturalis Biodiversity Center, and Fred Tuh Yit Yu (Sabah Parks) provided the collection numbers. Molecular work was performed at the DNA barcoding facility of Naturalis Biodiversity Center, which is funded by the Fonds Economische Structuurversterking. Herewith thanks to Kevin Beentjes and the staff from the DNA barcoding facility. My thanks also go to Kaspar Hendriks (Naturalis) for initiating the phylogenetic discussion and the anonymous reviewers for comments on the manuscript. This study was financially supported by the Netherlands Organisation for Scientific Research (NWO - ALW 821.01.002).

\section{References}

Aitchison JC, Ali JR, Davis AM. 2007. When and where did India and Asia collide? Journal of Geophysical Research 112: B05423. doi:10.1029/2006JB004706

Barrett RDH, Hebert PDN. 2005. Identifying spiders through DNA barcodes. Canadian Journal of Zoology 83: 481-491.

Borda E, Siddall ME. 2010. Insights into the evolutionary history of the Indo-Pacific bloodfeeding terrestrial leeches (Hirudinida: Arhynchobdellida: Haemadipsidae). Invertebrate Systematics 24: 456-472.

Borda E, Oceguera-Figueroa A, Siddall ME. 2008.On the classification, evolution and biogeography of terrestrial haemadipsoid leeches (Hirudinida: Arhynchobdellida: Hirudiniformes). Molecular Phylogenetics and Evolution 46: 142-154.

Britton T, Svennblad B, Erixon P, Oxelman B. 2007. Bayesian support is larger than bootstrap support in phylogenetic inference: a mathematical argument. Mathematical Medicine and Biology 24: 401-411.
Cottam M, Hall R, Sperber C, Armstrong R. 2010. Pulsed emplacement of the Mount Kinabalu granite, northern Borneo. Journal of the Geological Society, London 167: 49-60.

Folmer O, Black M, Hoeh W, Lutz R, Virjenhoek R.1994. DNA primers for amplification of mitochondrial cytochrome $\mathrm{c}$ oxidase subunit I from diverse metazoan invertebrates. Molecular Marine Biology and Biotechnology 3: 294-299.

Gillooly JF, Allen AP, West GB, Brown JH. 2005. The rate of DNA evolution: effects of body size and temperature on the molecular clock. Proceedings of the National Academy of Sciences of the United States of America 102: 140-145.

Govedich FR, Moser WE, Davies RW. 2004. Annelida, Hirudinea, Euhirudinea. Pp. 175-190in: Yule CM, Yong HS, eds, Freshwater Invertebrates of the Malaysian Region. Kuala Lumpur, Malaysia: Academy of Sciences.

Hall R. 2012. Late Jurassic-Cenozoic reconstructions of the Indonesian region and the Indian Ocean. Tectonophysics 570-571:1-41.

Hall R, Cottam M, Suggate S, Tongkul F, Sperber C, Batt G. 2008. The geology of Mount Kinabalu. Sabah Parks Publications 13: 1-76.

Hanebuth T, Stattegger K, Grootes PM. 2000. Rapid flooding of the Sunda Shelf: a late-glacial sea-level record. Science 288: 1033-1035.

Heaney LR. 1991. A synopsis of climatic and vegetational change in Southeast Asia. Climatic Change 19: 53-61.

Hebert PDN, Cywinska A, Ball SL, de Waard JR. 2003. Biological identifications through DNA barcodes. Proceedings of the Royal Society of London B 270: 313-321.

Hebert PDN, Penton EH, Burns JM, Janzen DH, Hallwachs W. 2004a. Ten species in one: DNA barcoding reveals cryptic species in the neotropical skipper butterfly Astraptes fulgerator. Proceedings of the National Academy of Sciences of the United States of America 101: 14812-14817.

Hebert PDN, Stoeckle MY, Zemlak TS, Francis CM. 2004b. Identification of birds through DNA barcodes. PLoS Biology 2(10): e312.

Huang J, Xu Q, Sun ZJ, Tang GL, Su ZY. 2007. Identifying earthworms through DNA barcodes. Pedobiologia 51: 301-309.

Jordaens K, van Riel P, Geenen S, Verhagen R, Backeljau T. 2001. Food-induced body pigmentation questions the taxonomic value of colour in the self-fertilizing slug Carinarion spp. Journal of Molluscan Studies 67: 161-167.

Lai Y-T, Nakano T, Chen J-H. 2011. Three species of land leeches from Taiwan, Haemadipsa rjukjuana comb. n., a new record of Haemadipsa picta Moore, and an updated description of Tritetrabdella taiwana (Oka). ZooKeys 139: 1-22.

Lohman, DJ, de Bruyn M, Page T, von Rintelen K, Hall R, Ng PKL, Shih H-T, Carvalho GR, von Rintelen T 2011. Biogeography of the Indo-Australian Archipelago. Annual Review of Ecology, Evolution and Systematics 42: 205-226.

Messing J. 1983. New M13 vectors for cloning. Methods in Enzymology 101: 20-78.

Moore JP. 1929. Leeches from Borneo with descriptions of new species. Proceedings of the Academy of Natural Sciences, Philadelphia 81: 267-295.

Moore JP. 1935. Leeches from Borneo and the Peninsular Malaysia. Bulletin of the Raffles Museum 10: 67-79.

Moore JP. 1938. Leeches (Hirundinea) principally from the Peninsular Malaysia, with descriptions of new species. Bulletin of the Raffles Museum 14: 64-79. 
Rougerie R, Decaëns T, Deharveng L, Porco D, James SW, Chang C-H, Richard B, Potapov M, Suhardjono Y, Hebert PDN. 2009. DNA barcodes for soil animal taxonomy. Pesquiera Agropecuaria Brasileira 44: 789-801.

Rowley J, Brown R, Bain R, Kusrini M, Inger R, Stuart B, Wogan G, Thy N, Chan-ard T, Trung CT, Diesmos A, Iskandar DT, Lau M, Ming LT, Makchai S, Truong NQ, Phimmachak S. 2010. Impending conservation crisis for Southeast Asian amphibians. Biology Letters 6: 336-338.

Smythies BE. 1960. Leeches of Borneo. Sarawak Museum Journal, New Series 9: 279-294.

Tamura K, Dudley J, Nei M, Kumar S. 2007. MEGA4: Molecular Evolutionary Genetics Analysis (MEGA) software version 4.0. Molecular Biology and Evolution 24: 1596-1599.

Voris HK. 2000. Maps of Pleistocene sea levels in Southeast Asia: shorelines, river systems and time durations. Journal of Biogeography 27: 1153-1167.
Wägele JW, Letsch H, Klussmann-Kolb A, Mayer C, Misof B, Wägele H. 2009. Phylogenetic support values are not necessarily informative: the case of the Serialia hypothesis (a mollusk phylogeny). Frontiers in Zoology 6: 12.

Wilke T, Schultheiß R, Albrecht C. 2009. As time goes by: A simple fool's guide to molecular clock approaches in invertebrates. American Malacological Bulletin 27: 25-45.

Woodruff DS. 2010. Biogeography and conservation in Southeast Asia: how 2.7 million years of repeated environmental fluctuations affect today's patterns and the future of the remaining refugial-phase biodiversity. Biodiversity and Conservation 19: 919-941.

Received: 17 May 2013

Revised and accepted: 18 November 2013

Published online: 20 December 2013

Editor: R. Sluys 


\section{Appendix}

Descriptions of the new Tritetrabdella species and subspecies

\section{Systematics}

Phylum: Annelida

Class: Clitellata

Subclass: Hirudinea

Order: Arhynchobdellida

Suborder: Hirudiniformes

Family: Haemadipsidae Blanchard, 1893

Genus: Tritetrabdella Moore, 1937

Tritetrabdella kinabaluensis spec. nov. (Figs 1-7)

The type of the new species is proposed to be the same as that of its nominal subspecies Tritetrabdella kinabaluensis kinabaluensis ssp. nov., namely, Sabah Parks collection number SP13398.

Tritetrabdella kinabaluensis kinabaluensis ssp. nov. (Figs 1-4, 6)

Material. One specimen from Gunung Alab and one from Kinabalu Park headquarters; both in $96 \%$ ethanol.

Type material of the new species and the nominal subspecies. Sabah Parks zoological collection, number SP13398. COI sequence: BOLD (Barcoding of Life) number KINTK001-13, GenBank accession number KF839948.

Type locality of the new species and the typical subspecies. Temperate mossy rain forest on acidic soils at Gunung Alab substation, Crocker Range, ca. 1900 m.a.s.l., ca 5.8297 N, 116.3422 E. Date: 21.09.2012, coll. N. Sol.

Other material of the typical subspecies. one individual from temperate rain forest at Kinabalu Park headquarters, Mount Kinabalu, ca. 1600 m.a.s.l., ca 6.0093 N, 116.5401 E. Date: 10.09.2012, coll. H. Kappes (SP13306). The COI sequence of SP13306 has the BOLD number KINTK002-13 and GenBank accession number KF839949.

Etymology. Named after the sacred mountain, Mount Kinabalu, in Crocker Range, Sabah, Borneo.

Diagnosis. Dorsum of unstressed individuals creamywhite with three darker, brownish stripes with black border, one median stripe located dorsally, the other two stripes supramarginally on each side (Fig. 3d). Brownish stripes somewhat variable in coloration (Fig. 3): middle field dark brown to median brown, bordered by rather broad blackish lines, loops form 'bubbles' or circles which reach the lateral stripes (Fig. 3), lateral stripes can appear almost blackish. The exact dorsal pattern differs individually. Mid-body somites with four annuli. Gonopores separated by only 3-3.5 annuli, posterior sucker with 55 rays. Well-defined by COI barcoding sequence.

Description- external characters. Body elongated, dorsoventrally flattened. Body length of type specimen after ethanol fixation ca. $9 \mathrm{~mm}$, width ca. $2 \mathrm{~mm}$ (see Fig. 3). Anterior sucker lateral diameter in ethanolpreserved specimen ca. $0.85 \mathrm{~mm}$. Posterior sucker dark, creamy-grey-brownish (but creamy in SP13306), with a rounded base area, pointed to anterior, 55 rays (Fig. 4). Posterior sucker diameter: $1.8 * 1.9 \mathrm{~mm}$. Auricles are trilobite, middle lobe smaller than lateral lobes, color yellowish to white. Head subtriangular to rounded, with 10 eyes that have a pigmented area towards the posterior end (Figs 3e, 4). Eyes are located at II ( $2^{\text {nd }}$ annulus), III ( $3^{\text {rd }}$ annulus), IV ( $4^{\text {th }}$ annulus), V ( $5^{\text {th }}$ annulus) and VI ( $8^{\text {th }}$ annulus) (Fig. 4). Mouth opening externally with two upward pointing ('smiling') edges (compare Fig. $3 \mathrm{e}$ ), internally with a triangular opening that is pointing frontally and gives view on another, rotated, triangular opening pointing distally (Fig. 5). Three jaws, i.e., trignathous. Venter flat, in living specimens uniformly pale, creamy-light-brown (Fig. 3d). However, the venter of the individual from Kinabalu Park Headquarters was orange, and the rest of the body became orange-brownish after an attempt to immobilize the specimen with freeze spray and preservation in ethanol (compare Fig. 3d, f). Eighty-two annuli. Somites I - IV uniannulate. Two and four polygonal areas in between the eyes in III and IV, respectively (e.g. Fig. 3e). Somite V on ventral side uniannulate, forming the buccal ring, on dorsal side biannulate ((a1a2)>a3). First dorsal annulus of this somite with eyes and six interocular areas. Somite VI on dorsal side triannulate, but on ventral side biannulate ((a1a2)>a3). Somite VII triannulate, somite VIII quadrannulate. Midbody somites IX-XXII quadrannulate, with equally sized annuli. Somites XXIII and XXIV triannulate. Somite XXV biannulate ((a1a2)>a3). Annuli with irregular polygonal areas. At their dorsoventral margins, (a1a2) and a 3 form the $1^{\text {st }}$ and $2^{\text {nd }}$ auricular lobes, respectively. Somite XXVI uniannulate, forming irregular areas. At its dorso-ventral margin, XXVI constitutes the $3^{\text {rd }}$ auricular lobe. Somite XXVII uniannulate (that is, the $82^{\text {nd }}$ annulus), with anus. Clitellum unknown. Gonopores separated by 3.5 annuli (Fig. 4): male gonopore between $27^{\text {th }}$ and $28^{\text {th }}$ annulus (somite $\mathrm{XI}$ ); female gonopore in $31^{\text {st }}$ annulus (somite XII). 

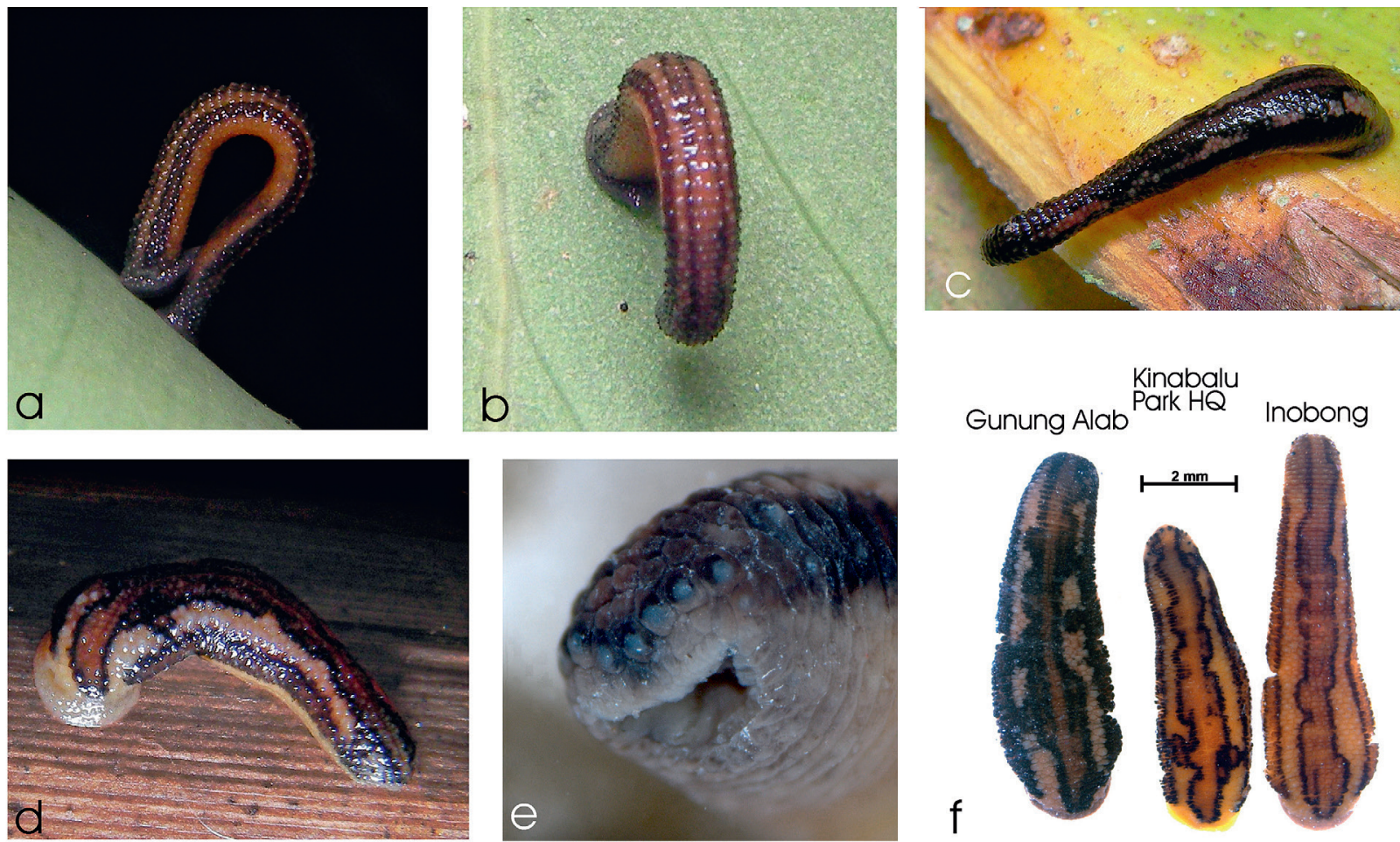

Fig. 3. Color variation in Tritetrabdella kinabaluensis spec. nov. from the three locations: a) and b) T. $k$. inobongensis ssp. nov. from Inobong substation; c) T. k. kinabaluensis ssp. nov. (SP13398) from Gunung Alab; d) T. k. kinabaluensis ssp. nov. (SP13306) from Kinabalu Park Headquarters; e) ventro-lateral closeup of the head region (SP13398, ethanol-preserved); f) comparison of ethanol-preserved individuals (from left to right: SP13398, SP13306, and SP13383; lateral incisions are from tissue removal for DNA extraction). The yellowish color in the preserved SP13306 occurred during ethanol preservation.
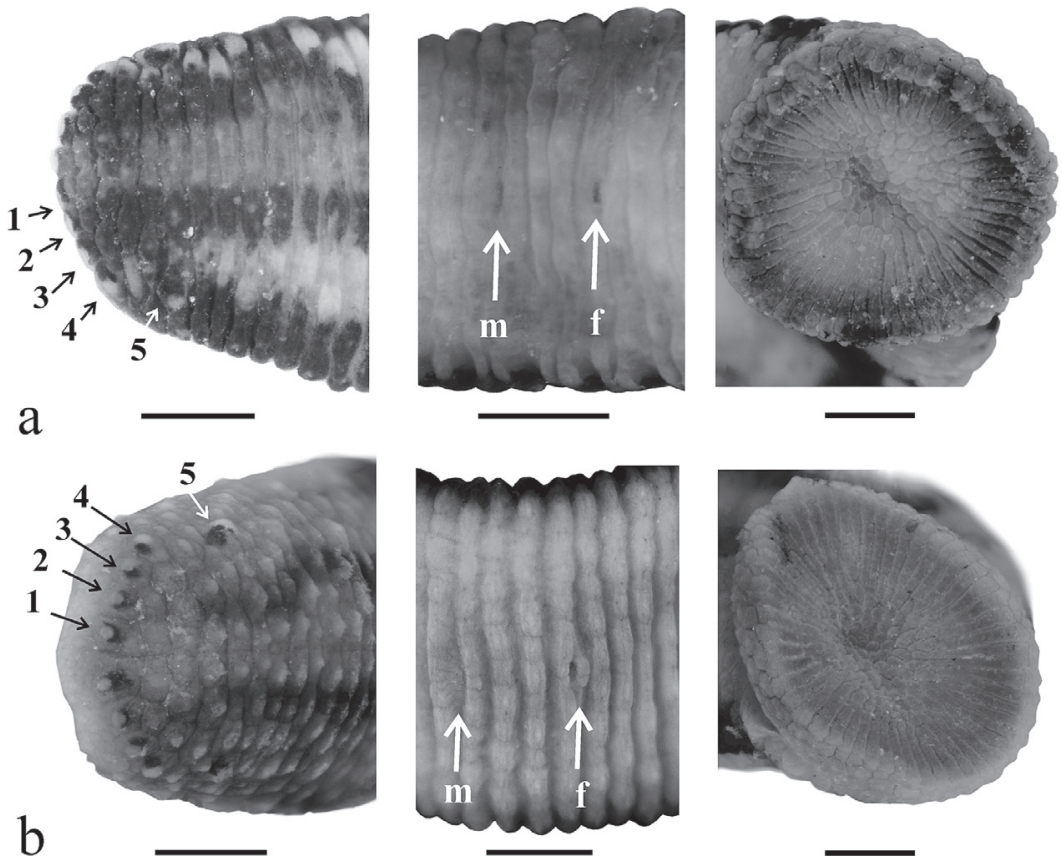

Fig. 4. Details of the head, the gonopores, and the caudal sucker (each with 55 rays) of ethanol-preserved individuals of Tritetrabdella kinabaluensis spec. nov. in a) the kinabaluensis species and subspecies type (SP 13398) and b) the inobongensis subspecies type (SP 13383). Scale bar: $0.5 \mathrm{~mm}$ each. 
Gonopore area slightly darkened in the specimen from Alab (SP13398; see Fig. 4), but same color as the venter in the specimen from Kinabalu Park Headquarters (SP13306).

Anatomy of the genital system. Internal anatomical descriptions follow the terms used in Borda et al. (2008). Male gonopore in XI internally connected to rounded atrium. Nerve cord passes atrium on right side. Ejaculatory ducts thick and short, connecting atrium to ejaculatory bulbs. Atrium, ejaculatory duct, and the anterior part of the ejaculatory bulbs are adjoined by a layer of prostate glands. Ejaculatory bulbs elongated ellipsoid, in ethanol-preserved specimen $0.76 \mathrm{~mm}$ long and ca. $0.21 \mathrm{~mm}$ broad, placed latero-posteriorly to the atrium. The distal parts of the ejaculatory bulbs continue as sperm ducts. Sperm ducts extending posteriorly, curved, relatively vage and slender, only slightly thicken lateroposterior of the oviducal glanular sac. Sperm ducts run laterally to the oviducal glanular sac and could not be traced after somite XVI. Female gonopore in XII internally extending posteriorly as the vaginal duct. Nerve cord passes vaginal duct on left side. Vaginal duct curved, in ethanol-preserved specimen 0.10-0.14 mm thick, in full extension ca. $1 \mathrm{~mm}$ long. Oviducal glanular sac in XIII-XV, ovate and elongated, ca. $0.9 \mathrm{~mm}$ long and $0.57 \mathrm{~mm}$ wide within ethanol-preserved specimen, ca. $1.09 \mathrm{~mm}$ long and $0.52 \mathrm{~mm}$ wide after isolation. Ovaries in XII, oviduct somewhat shorter (ca. $0.5 \mathrm{~mm})$ than the common oviduct $(0.3 \mathrm{~mm})$ that connects the ovaries to the oviducal glanular sac.

Distribution. So far, only known from two locations, namely Gunung Alab in Crocker Range National Park and Mount Kinabalu Park Headquarters, in Sabah, Borneo, at altitudes between 1500 and 1900 m.a.s.l.

Ecology. So far, only known from cold and moist mossy temperate rain forests on acidic soils, one at an often cloud-covered mountain top. Its host(s) are unknown, but the two specimens somehow were attracted to man.

Conservation status. Data deficient, needing urgent assessment. If Tritetrabdella leeches depend on amphibians (Lai et al., 2011), which across SE Asia face critical population declines because of habitat loss (e.g. Rowley et al., 2010), the leeches may be threatened by both, habitat and host loss.

Discussion. In contrast to the completely yellowish T. scandens (Borda and Sidall 2011: 464), the new species has brownish filled stripes, that, however, are somewhat variable in coloration (Fig. 3). Also, the light areas in between the dorsal pattern and lateral stripes are creamy and thus differ from the yellowish T. scan- dens. The COI barcoding sequence, as well as the COI protein sequence, of the Bornean material clearly differ from the two previously described Tritetrabdella species from SE Asia (Figs 1-2). The COI barcoding sequence also differs between Tritetrabdella kinabaluensis kinabaluensis ssp. nov. and T. kinabaluensis inobongensis ssp. nov. (described below).

Tritetrabdella kinabaluensis inobongensis ssp. nov. (Figs 1-7)

Material. Four specimens, all four from Inobong substation.

Type material. Sabah Parks zoological collection, collection number SP13383; COI sequence: BOLD number KINTK006-13, GenBank accession number KF839947.

Paratypes. Sabah Parks zoological collection, collection numbers SP13380, SP13381, SP13382, BOLD numbers KINTK003-13, KINTK004-13, KINTK005-13, respectively, and GenBank accession numbers KF839944, KF839945, KF839946, respectively.

Type locality. Valley below Sungai Kibambangan waterfall near Inobong substation, Crocker Range, ca. 5.8551 N, 116.1402 E. Date: 18.09.2012, H. Kappes leg., lowland dipterocarp broadleaved floodplain forest with some herbs, richly structured by rocks and woody debris.

Etymology. Named as coming from the Inobong substation in Crocker Range, Sabah, Borneo, where the specimens were collected.

Diagnosis. Overall of medium-brown appearance, dorsum color yellow-brown, with three somewhat midbrownish stripes that have a brownish border, one dorsal median stripe and two lateral stripes. Outline of the median stripe occasionally with loop-bubbles that seemingly do not reach the lateral stripes. Venter yellowish orange-brown. Mid-body somites with four annuli. Gonopores separated by only 3-3.5 annuli, posterior sucker with 55 rays. Well-defined by COI barcoding sequence.

Description - external characters. Similar in shape, size and head structures to nominal subspecies T. $k$. kinabaluensis ssp. nov., however, it is lighter in body color. Median stripe with occasional lateral loop-bubble pattern that did not reach the lateral stripes in the available specimens. Stripes brown, and basal color light brown to yellowish-brown rather than creamy whitish brown. Venter orange-brown (Figs 3a and b). Distal sucker dark grey-brown, more pointed towards the front (Fig. 4), a feature that can also be observed in living 

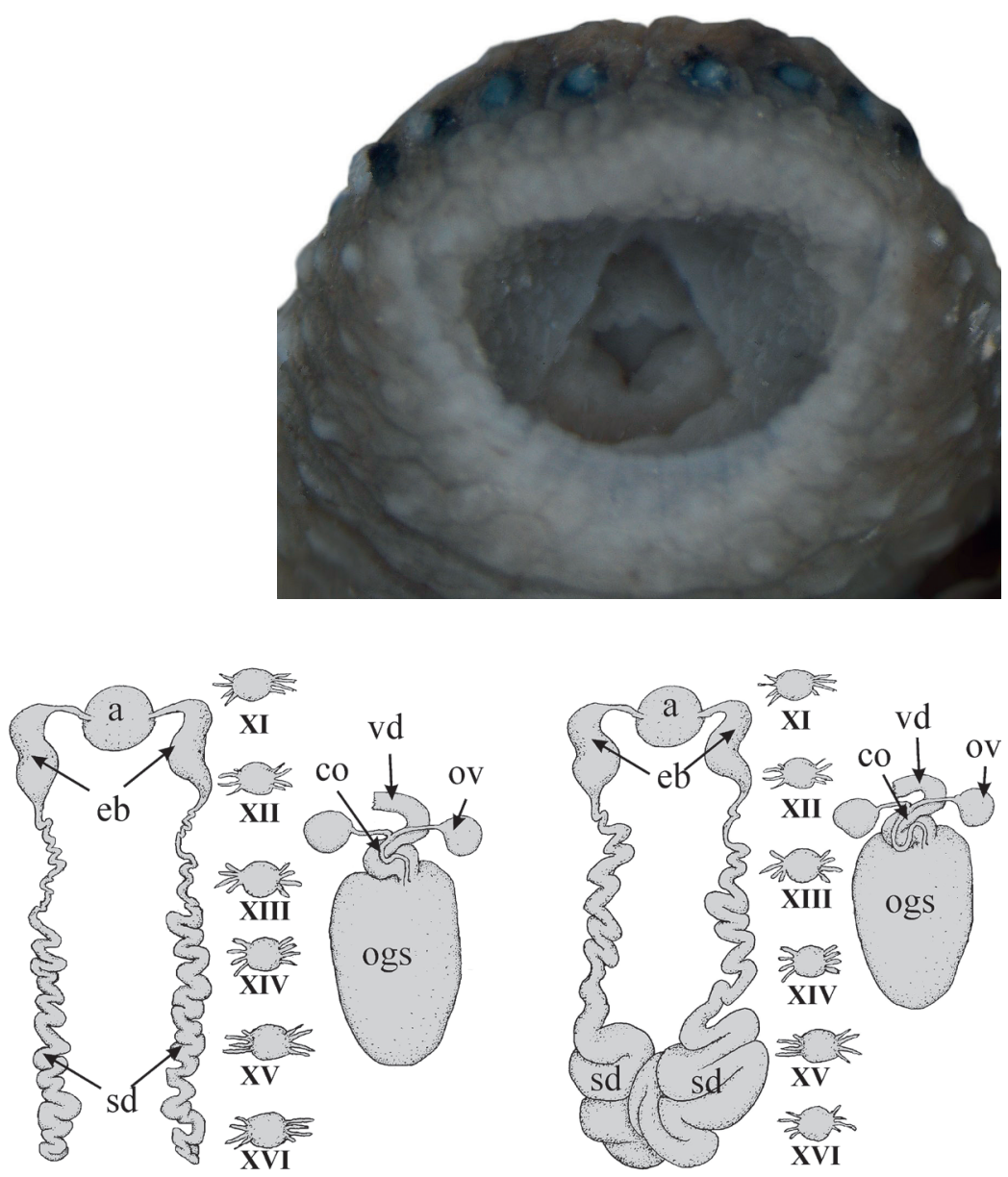

$\mathbf{a}$

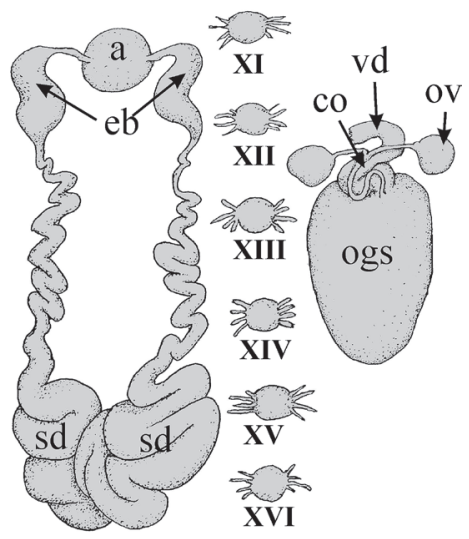

b

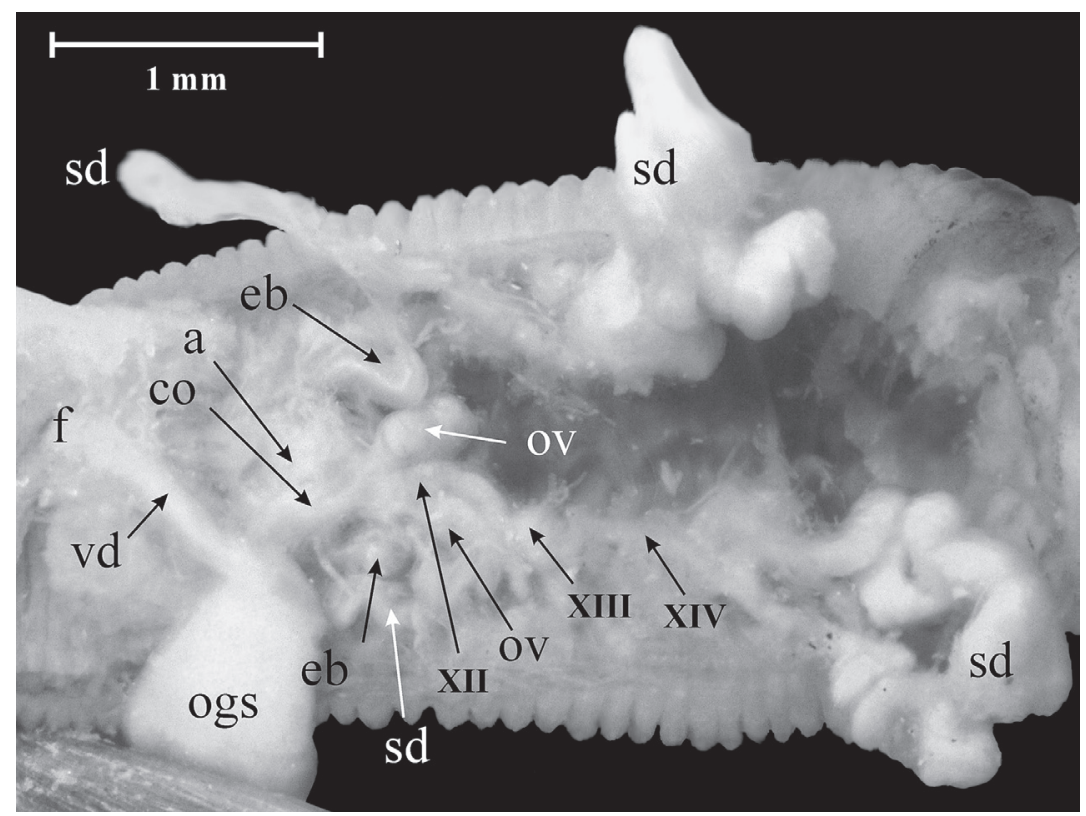

Fig. 5. Ventral view of the head of Tritetrabdella kinabaluensis inobongensis ssp. nov. (SP13398), showing the internal structure of the frontal sucker (frontal sucker from edge to edge 0.86 mm wide)

Fig. 6. Schematic outline of the genital system of a) Tritetrabdella kinabaluensis kinabaluensis spec. nov. ssp. nov. (SP 13398) b) Tritetrabdella kinabaluensis inobongensis nov. ssp (SP13383). Abbreviations: a: atrium, co: common oviduct, eb: ejaculatory bulb, f: female gonopore, g: ganglion, ogs: oviducal glanular sac, ov: ovaries, sd: sperm ducts, vd: vaginal duct, XI-XVI: ganglion segment numbers.
Fig. 7. Lower genital tract of Tritetrabdella kinabaluensis inobongensis ssp. nov. (SP 13383, ethanol-preserved) as seen under a microscope, venter flapped towards the anterior, oviducal glanular sac shifted to the right of the specimen. Abbreviations: a: atrium, co: common oviduct, eb: ejaculatory bulb, f: female gonopore, g: ganglion, ogs: oviducal glanular sac, ov: ovaries, sd: sperm ducts, vd: vaginal duct, XII-XIV: ganglion segment numbers. 
specimens (Fig. 3a). Posterior sucker diameter in ethanol-preserved specimen ca. $1.8 * 2.0 \mathrm{~mm}$, with 55 rays as in nominal subspecies. Body annulation as in the nominal subspecies (see above).

Anatomy of the genital system (SP13383). Male gonopore in XI internally connected to rounded atrium. Nerve cord passes atrium on right side. Ejaculatory ducts thick and short, connecting atrium to ejaculatory bulbs. Atrium, ejaculatory duct, and the anterior part of the ejaculatory bulbs are adjoined by a layer of prostate glands. Ejaculatory bulbs elongated ellipsoid, curved, in ethanol-preserved specimen ca. $0.5 \mathrm{~mm}$ long (ca. $0.65 \mathrm{~mm}$ if fully extended) and up to $0.2 \mathrm{~mm}$ broad, placed latero-posteriorly to the atrium. The distal part of the ejaculatory bulbs continues as sperm ducts. Sperm ducts extending posteriorly to the anterior border of XVII, curved, initially vage and slender, but thick and conspicious posterior of the oviducal glanular sac (compare Figs $6 b, 7)$. Sperm ducts run laterally to the oviducal glanular sac, then slightly overlay each other in their thickened part in XV and XVI, but remain easy to separate during dissection. Female gonopore in XII internally extending posteriorly as the vaginal duct. Nerve cord passes vaginal duct on right side. Vaginal duct curved, ca. $0.14 \mathrm{~mm}$ thick, in full extension $1 \mathrm{~mm}$ long in ethanol-preserved specimen. Oviducal glanular sac in XII-XIV, ovate and elongated, ca. $1.1 \mathrm{~mm}$ long and $0.55 \mathrm{~mm}$ wide in ethanol-preserved specimen.
Ovaries in XII, oviduct somewhat shorter $(0.3 \mathrm{~mm})$ than the common oviduct $(0.44 \mathrm{~mm})$ that connects the ovaries to the oviducal glanular sac.

Distribution. So far, only known from the type locality in Crocker Range.

Ecology. So far, only known to occur in low altitude dipterocarp forests. Its host(s) are unknown, but the specimens seemed to be attracted by man.

Conservation status. Data deficient, as for the nominal subspecies.

Discussion.T.k.inobongensis is tentatively assigned to subspecies status (see results section). It has a lighter color appearance than the typical T. k. kinabaluensis ssp. nov.. The outline of the pattern somewhat thinner than in T.k. kinabaluensis ssp. nov., and brownish instead of blackish (see Fig. 3a-b). T. k. inobongensis differs in COI barcoding sequence from the typical subspecies, but not in protein sequence (Figs 1-2). From what can be seen in the few specimens analyzed so far, its COI barcoding sequence has a slightly higher $\mathrm{C}$ content $(>15 \%)$ than that of the typical subspecies $(<15 \%)$ (Table 2). More adult material is needed to assess if anatomical differences (see above) are a diagnostic feature or (partially) driven by life cycle. Parts of the genital tract in the typical T. $k$. kinabaluensis ssp. nov. might not have been fully developed, or already aged, when compared to the inobongensis subspecies (Fig. 6). 